\title{
Sorption and diffusion of dense carbon dioxide in a biocompatible polymer
}

\author{
Ana Rita C. Duarte ${ }^{\mathrm{a}}$, Carlos Martins ${ }^{\mathrm{a}}$, Patrícia Coimbra ${ }^{\mathrm{b}}$, Maria H.M. Gil ${ }^{\mathrm{b}}$, \\ Hermínio C. de Sousa ${ }^{b}$, Catarina M.M. Duarte ${ }^{a, *}$ \\ ${ }^{a}$ Nutraceuticals and Delivery Laboratory, ITQB/IBET, Apartado 12, 2780-901 Oeiras, Portugal

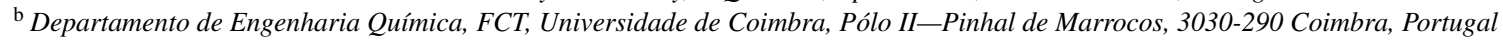

Received 28 July 2005; received in revised form 7 November 2005; accepted 2 December 2005

\begin{abstract}
Mass sorption and diffusion coefficients in one acrylate biocompatible copolymer contacted with supercritical (sc) carbon dioxide are reported. Equilibrium solubility of dense carbon dioxide in poly(methylmethacrylate-co-ethylhexylacrylate-co-ethyleneglycoldimethacrylate) (P(MMAEHA-EGDMA)) was studied by a gravimetric method in a temperature range from 308 to $323 \mathrm{~K}$ and a pressure range from 10.0 to $20.0 \mathrm{MPa}$. The cross-linked copolymer presented Fickian behavior and Fick's diffusion model was applied to determine the amount of carbon dioxide present and the diffusion coefficients. Diffusion coefficients for the sorption under supercritical conditions and desorption at ambient conditions were determined and compared. Samples of P(MMA-EHA-EGDMA) with different thickness were used for comparison of the maximum sorption degree. Polymerization conditions were also varied in order to evaluate the influence of the molecular weight of the copolymer in the $\mathrm{CO}_{2}$ sorption process. To investigate the possibility of impregnating this acrylate copolymer with an anti-inflammatory drug, a preliminary experiment was performed. (C) 2005 Elsevier B.V. All rights reserved.
\end{abstract}

Keywords: Sorption; Diffusion; Fick's law; Biocompatible polymers; Supercritical fluids

\section{Introduction}

The behaviour of different classes of polymers in supercritical (sc) media, mainly in supercritical carbon dioxide, has been widely studied in recent years. The manipulation of the physical properties as well as their selective control has become an area of interest in polymer science, particularly in polymers synthesis and processing [1,2].

This work is part of a research project designed for the development, preparation and characterization of improved controlled drug release systems (CDS) with ophthalmic applications. The biocompatible cross-linked acrylate copolymer poly(methylmethacrylate-co-ethylhexylacrylate-co-ethyleneglycoldimethacrylate) (P(MMA-EHA-EGDMA)) has been proposed by Mariz [3] as a promising matrix to be used for intraocular delivery of anti-inflammatory drugs used in eye surgery. The structures of the correspondent monomers are presented in Fig. 1.

\footnotetext{
* Corresponding author. Fax: +351214421161.

E-mail address: cduarte@itqb.unl.pt (C.M.M. Duarte).
}

The use of supercritical fluids as solvents offers the possibility to develop new "clean and environmental friendly" processes for the preparation of CDS. Compressed carbon dioxide has excellent plasticizing properties and can swell most biocompatible polymeric matrixes, thus promoting drug impregnation processes. Biologically active or medical ingredients can be incorporated into polymer substrates without interference on the activity of the active substance because supercritical fluid processing operates at mild conditions [4,5]. Carbon dioxide is the most commonly used fluid due to its non-toxic properties and to the low operation temperatures involved in supercritical processes $\left(T_{\mathrm{c}}=31^{\circ} \mathrm{C}\right.$ and $P_{\mathrm{c}}=73$ bar $)$ [6].

It is well known that when a low molecular weight compound, such as carbon dioxide, comes into contact with the polymer, sorption of the low molecular weight species by the polymer occurs. Carbon dioxide at high pressure can be dissolved in a polymeric matrix; the result is the swelling of the polymer since molecular forces are established between the two species [7]. Thus, working under sc conditions is of great interest due to the possibilities of modifying the morphological and functional properties of polymers by swelling in $\mathrm{sc}^{\mathrm{CO}_{2}}$. Carbon dioxide is used as a temporary plasticizer to assist the absorption of 


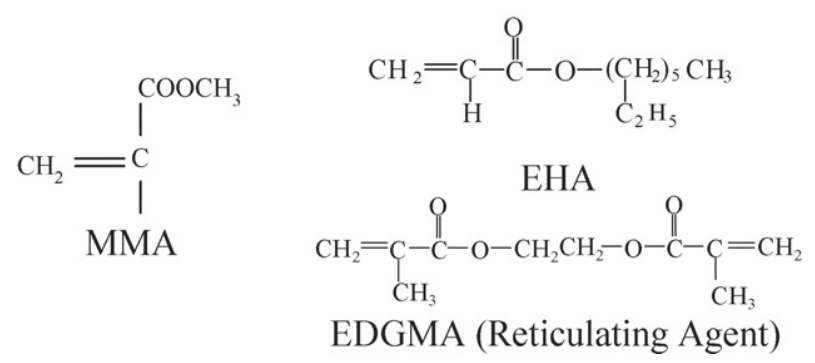

Fig. 1. Chemical structure of the monomer molecules present in the copolymer.

additives into glassy or rubbery polymers [8] as it promotes an increase in the linear dimension of the polymer [5], enhancing the kinetics of absorption of the diffusing substances. Another great advantage of working under supercritical media is that the fluids are gases at room temperature and atmospheric pressure. They are rapidly dissipated, leaving no toxic solvent residue behind and can be easily recovered upon release of pressure $[9,10]$. Finally, due to the environmentally friendly properties of supercritical carbon dioxide, it is possible to substitute toxic organic solvents in several processes.

The determination of the best operating conditions for the supercritical fluid impregnation of pharmaceuticals into biopolymers involves the knowledge of the solubility and diffusion coefficients of compressed carbon dioxide in the polymeric matrixes.

Sorption and swelling of polymers are frequently measured using different methods. Literature data on the sorption of carbon dioxide into polymers refer various apparatus and methods to perform the measurements. The use of a quartz-crystal microbalance and a gravimetric method or a barometric method are the most commonly used $[11,12]$. Transmission IR spectroscopy has also been used to measure the sorption of polymers $[13,14,24]$. In regards to measurements on polymer swelling, the direct observation of the sample's dimensions is widely used [7].

In this work, experimental measurement of the solubility of carbon dioxide in the polymeric matrix was obtained by a gravimetric procedure and the sorption and desorption diffusion coefficients were determined.

The concept of the gravimetric procedure is to expose the sample to carbon dioxide and after depressurization to atmospheric pressure transfer the sample to a balance recording the weight changes. Supported on Fick's laws of diffusion the amount of $\mathrm{CO}_{2}$ (immediately before depressurization) was extrapolated.

The mathematical treatment of the polymers depends on whether the polymer is in the rubbery or glassy state that is, whether above or below its glass transition temperature $\left(T_{\mathrm{g}}\right)$. When the diffusing substance causes extensive swelling of the polymer it exhibits an "anomalous" or "non-Fickian" behaviour. This is the case with the so-called glassy polymers $[15,16]$. In rubbery polymers, like P(MMA-EHA-EGDMA), on the other hand, the diffusion is generally Fickian. The main difference is that polymers in the rubbery state respond rapidly to changes in their condition whereas in the glassy state they do not. This is a consequence of the mobility of the polymer chains. In polymers well above its $T_{\mathrm{g}}$ the molecules participate in the diffusion process adjusting them self to the presence of the penetrant $[4,15,16]$.

\section{Experimental}

\subsection{Materials}

Methyl methacrylate (MMA) (CAS 80-62-6, 99.9\% purity) was purchased from Fluka. Hydroquinone, its polymerization inhibitor, was removed by liquid-liquid extraction with an aqueous solution of sodium hydroxide and sodium chloride. 2-Ethylhexylacrylate (EHA) (CAS 103-11-7, 98.0\% purity), ethyleneglycoldimethacrylate (EGDMA) (CAS 97-90-5, 98.0\% purity) and benzoyl peroxide (CAS 94-36-0, 70.0\%) purity, as a thermal initiator, were purchased from Sigma Aldrich. Carbon dioxide (99.998 mol\%) was supplied by Air Liquide.

\subsection{Polymerizations}

Poly(methylmethacrylate) (PMMA) and the copolymer poly(methylmethacrylate-co-2-ethylhexylacrylate-co-ethyleneglicoldimethacrylate), were synthesized by bulk free radical polymerization, and according to the method described by Mariz [3].

Reaction mixtures were prepared weighing the liquid monomers and the thermal initiator. The cross-linked copolymer P(MMA-EHA-EGDMA) was prepared adding $40 \%$ of MMA, $60 \%$ EHA and $7.5 \%$ (weight $\%$ of total mass of MMA + EHA) of the cross-linking monomer, EGDMA. Two different amounts of benzoyl peroxide were used $0.25 \%$ and $1 \%$ (molar\% of total moles of MMA + EHA).

In all cases, reaction mixtures were magnetically stirred for 10 min until benzoyl peroxide was completely dissolved. Then, the resulting mixtures were spread between glass plates, separated with silicone rubber spacers, in order to produce fine polymer films of uniform thickness. Polymerization reactions were carried out for $3 \mathrm{~h}$, in a heated oven, at $353.15 \mathrm{~K}$. For PMMA, temperature was gradually raised from 323.15 to $353.15 \mathrm{~K}$ by increments of $5^{\circ}$ every $15 \mathrm{~min}$. For all cases films with different thicknesses were prepared $(0.5,1.0$ and $2.0 \mathrm{~mm})$. The samples were cut in circular shape samples ( $9.0 \mathrm{~mm}$ diameter). All samples were vacuum dried and weighted, until constant mass is achieved.

\subsection{Sorption measurements}

The solubility of $\mathrm{CO}_{2}$ in the matrixes was obtained using a simple gravimetric procedure. The high-pressure apparatus is schematically presented in Fig. 2. The solubility measurements were performed in a similar manner to that described by Berens et al. [8]

A new stainless steel cell was designed to perform these experiments. A quick opening cell is required in order to minimize the time between depressurisation and the acquisition of the data, this usually took $40 \mathrm{~s}$. The sorption of $\mathrm{CO}_{2}$ into the polymer film was done in this high-pressure vessel followed by 


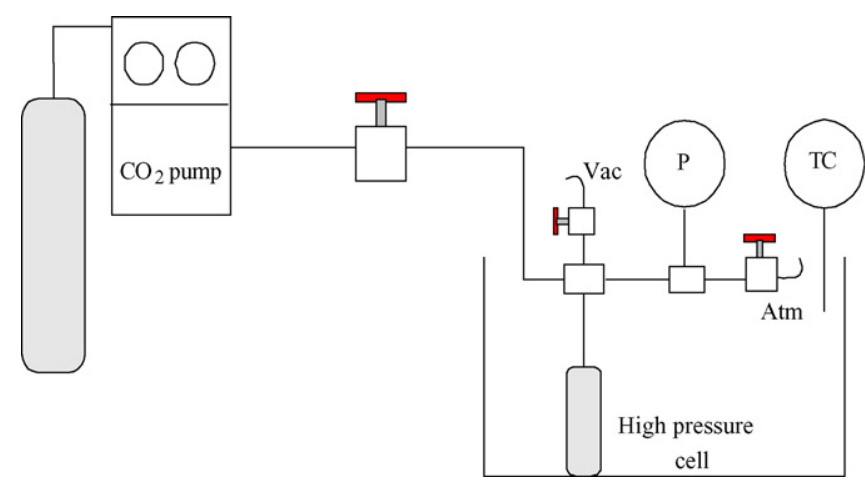

Fig. 2. Schematic diagram of the high pressure sorption apparatus (P, pressure transducer; TC, temperature controller).

rapid depressurisation of the sample. A compromise has been established between the velocity of depressurisation and opening of the cell, so that carbon dioxide would not freeze inside. Also, the volume of the cell plays an important role in preventing the $\mathrm{CO}_{2}$ to freeze; this becomes more evident for the experiments with lower time of exposure. For this reason the volume of the cell has to be as small as possible.

The cell is immersed in a thermostatic water-bath, heated by means of a controller that maintained temperature within $\pm 0.1 \mathrm{~K}$. The sample was loaded in a small stainless steel basket and the initial weight was recorded; the basket was placed inside the cell which was then evacuated for $15 \mathrm{~min}$. Carbon dioxide is pumped into the cell using a pneumatic compressor until the desired pressure is attained. The pressure inside the cell is measured with a pressure transducer within \pm 0.5 bar. The samples were submitted to high pressure for different periods of time from $2 \mathrm{~min}$ to $20 \mathrm{~h}$. After impregnation the vessel is quickly depressurised and the basket with the sample transferred to the balance for recording weight changes during desorption at atmospheric pressure.

To test and validate the new apparatus, some experiments were performed using PMMA, at $10 \mathrm{MPa}$ and $313 \mathrm{~K}$. The calculation of the diffusion coefficient of this polymer proved to be in the same order of magnitude of the literature, $10^{-7}$ to $10^{-5} \mathrm{~cm}^{2} / \mathrm{s}$, depending on $\mathrm{Mw}$ of the polymer samples [17,18] validating our experimental method. Furthermore, the maximum sorption degree $(16 \%)$ is also in very good agreement with literature data obtained by a spectroscopic in situ method [19].

\subsection{Data analysis}

The mathematical theory of diffusion through isotropic substances was first studied by Fick (1855). This theory is based on the hypothesis that the rate transfer of a diffusing substance through unit area of a section is proportional to the concentration gradient measured normal to the section, i.e.,

$J=-D \frac{\partial C}{\partial x}$

where $D$ is the diffusion coefficient, $C$ the concentration of the diffusion substance, $x$ the coordinate perpendicular to the section and $J$ is the flux per unit of area. This is known as Fick's first law of diffusion.

The differential equation of diffusion, known as Fick's second law derives from the first one and if the diffusion is onedimensional, i.e., if there is a gradient concentration in only one direction (along the $x$-axis), the amount of diffusing substance in the element is given by the expression:

$$
\frac{\partial C}{\partial t}=D \frac{\partial^{2} C}{\partial x^{2}}
$$

A particular solution of the differential equation (Fick's second law of diffusion) describing the time dependence of the diffusing material out of the sample, that in our case is a slab of thickness $l$, can be derived, considering that there is a uniform initial distribution and that the surface concentrations are equal, the boundary conditions are: $[4,15,16,20]$.

$C=0$ for $x=0$ and for $x=l$, at $t=0$, where $l$ is the thickness of the film

and

$C=C_{0}$ for $0<x<1$, at $t=0$.

$M(t)=\frac{8 M_{0}}{\pi^{2}} \sum_{n=0}^{\infty} \frac{1}{(2 n+1)^{2}} \mathrm{e}^{\left[((-(2 n+1) / 1) \pi)^{2} D t\right]}$

where $M(t)$ is the mass of diffusing substance at time $t$ and $M_{0}$ is the equilibrium sorption attained theoretically after infinite time.

The analytical solution of Fick's second law of diffusion, that describes the sorption process, results from the application of the Laplace transform to Eq. (2) $[15,16]$ :

$$
\frac{M(t)}{M_{0}}=1-\frac{8}{\pi^{2}} \sum_{n=0}^{\infty} \frac{1}{(2 n+1)^{2}} \exp \left(\frac{-D_{\mathrm{s}}(2 n+1)^{2} \pi^{2} t}{l^{2}}\right)
$$

This equation can be simplified by truncating at the first term in the summation:

$$
\frac{M(t)}{M_{0}}=1-\frac{8}{\pi^{2}} \exp \left(\frac{-D_{\mathrm{s}} \pi^{2} t}{l^{2}}\right)
$$

For a constant sorption diffusion coefficient the graph for a sorption experiment is a straight line, to within the normal limits of the experimental error, as much as about $60 \%$, therefore, the diffusion coefficient can be obtained from the slope of $\ln \left(1-\left(M(t) / M_{0}\right)\right)$ as a function of $\left(t / l^{2}\right)$.

\section{Results and discussion}

\subsection{Sorption of $\mathrm{CO}_{2}$}

The linear relationship between amount of carbon dioxide dissolved in the polymer and the square root of desorption time validates the assumption that the copolymer follows a Fickian diffusion (Fig. 3). Therefore, Eq. (3) can be used to calculate the best values for the desorption diffusion coefficient and $M(t)$, the later being estimated by the extrapolation to zero desorption time. The data set describing the mass of $\mathrm{CO}_{2}$ present in the samples as a function of time after the pressure release recorded 


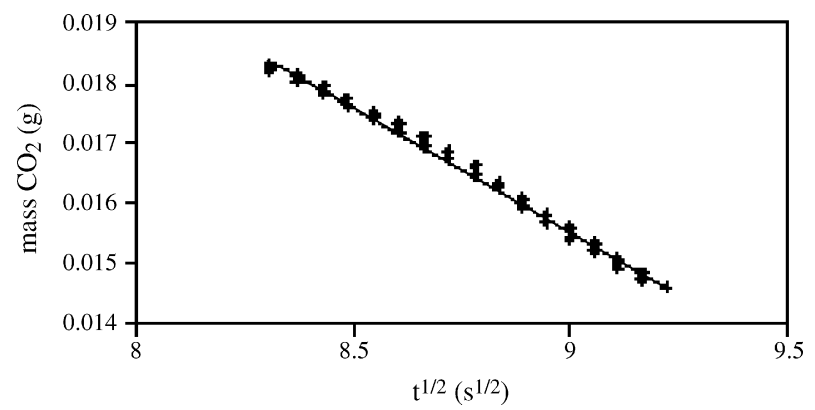

Fig. 3. Plot of the mass of $\mathrm{CO}_{2}$ measured vs. the square root of time for the experiment performed at $15.0 \mathrm{MPa}, 323 \mathrm{~K}$ during $16.5 \mathrm{~h}$, copolymer ( $1 \mathrm{~mm}$ thick).

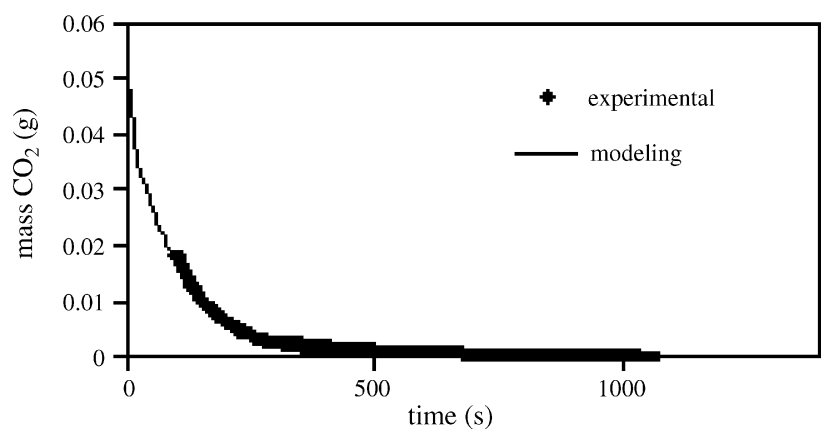

Fig. 4. Desorption curve for the reticulated copolymer (1 mm thick) after an exposure time of $4 \mathrm{~h}$ at $18.0 \mathrm{MPa}$ and $313 \mathrm{~K}$.

by the balance is exported to an ASCII file which is going to be used for modeling of the experiments, by an iterative process. An estimation of $D$ (desorption diffusion coefficient) and $M(t)$ is made and the theoretical desorption curve can be modeled. The validity of the Fickian approach is proven by the match of the experimental desorption curve and the theoretical one, as it can be seen in Fig. 4. The error associated with the determined $M(t)$ was found to be $\pm 15 \%$.

The effect of the thickness of the samples on the maximum sorption degree was studied. The sorption degree was defined to be the ratio between the mass of carbon dioxide in the sample and the total mass (mass of the polymeric sample + mass of carbon dioxide). Experiments on slabs of three different thicknesses $(0.5,1$ and $2 \mathrm{~mm})$ were performed and no significant differences were observed regarding the percentage of carbon dioxide present on the samples (Fig. 5).

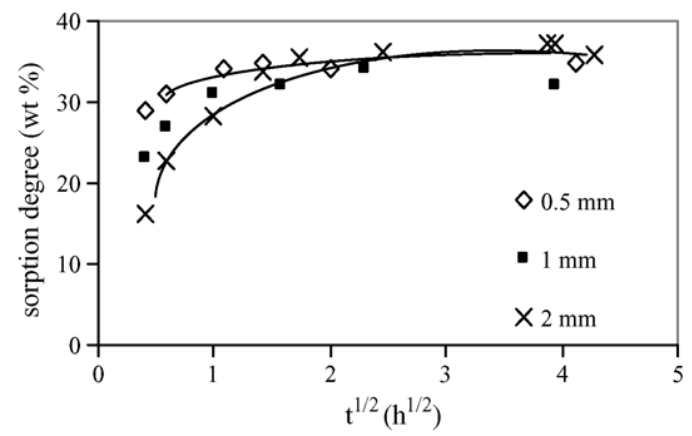

Fig. 5. Sorption curves for the copolymers with different thicknesses exposed to $10.0 \mathrm{MPa}$ and $313 \mathrm{~K}$.

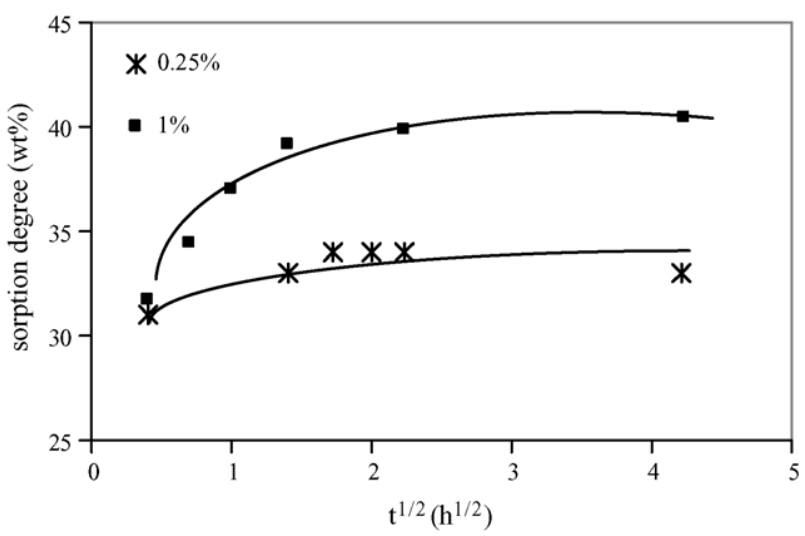

Fig. 6. Sorption curves for the copolymers ( $1 \mathrm{~mm}$ thick) prepared with different percentages of initiator and exposed to $15.0 \mathrm{MPa}$ and $313 \mathrm{~K}$.

The polymer swelling was determined by in-situ spectroscopic techniques and it is described elsewhere [24]. The diffusion length is not significantly alters by the swelling of the polymer. Some calculations were made in order to check the effect of a small increase in the thickness in the modelling of experimental data and this parameter does not influence the results obtained.

Polymerization conditions were varied in order to evaluate the influence of the molecular weight of the copolymer in the $\mathrm{CO}_{2}$ sorption process. Two percentages of initiator $(0.25$ and $1 \% \mathrm{wt}$.) were used and it was observed that the maximum sorption degree of $\mathrm{CO}_{2}$ corresponds to the situation when the copolymer was prepared with a higher percentage of initiator. The quantity of initiator used in the polymerization process influences the molecular weight of the polymer but it does not have a significant influence on the reticulation of the polymer, because the cross-linking agent (EGDMA) is very reactive. As it is a crosslinked copolymer it was not possible to determine the molecular weight of the samples. Theoretically, a higher percentage of initiator will lead to the production of a copolymer with short polymer chains and consequently, a lower molecular weight. The diffusion of carbon dioxide is facilitated because of the higher polymer chain mobility and in this case a higher sorption degree is observed (Fig. 6).

The effect of pressure and temperature was also studied in a pressure range from 10.0 to $20.0 \mathrm{MPa}$ and a temperature range from 308 to $323 \mathrm{~K}$.

Fig. 7 shows the sorption curves at $313 \mathrm{~K}$ for the three pressures studied, where the sorption degree is plotted as a function of the square root of time. The sorption amount increases with time of exposure until the equilibrium is reached. Regarding this copolymer the equilibrium was reached after $1 \mathrm{~h}$ of exposure. The maximum sorption degree is plotted as a function of pressure for each temperature studied (Fig. 8). For each isotherm, the maximum sorption degree increases with increasing pressure. In contrast, the solubility of $\mathrm{CO}_{2}$ in the polymer decreases with increasing temperature. At a higher temperature the kinetic motion of the supercritical fluid increases resulting in a decrease of the sorption amount. At a higher density region, lower temperatures, more $\mathrm{CO}_{2}$ is adsorbed into the polymer, as it is illustrated in Fig. 9. Similar behavior has been reported by other authors 


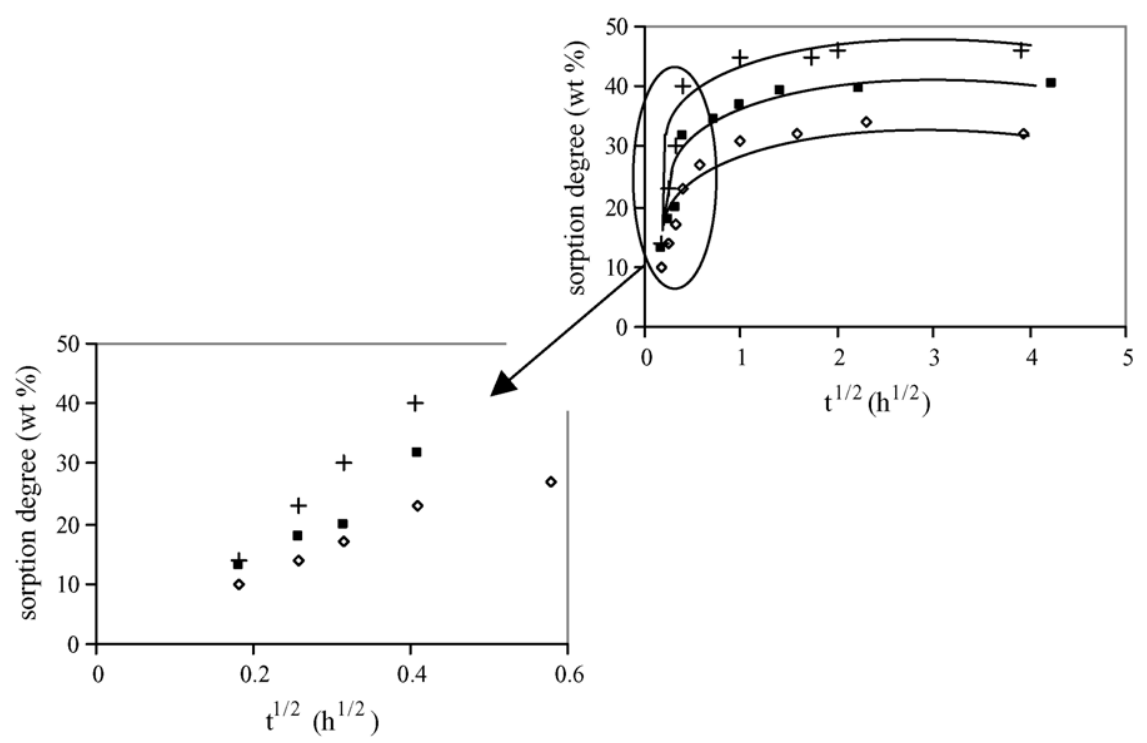

Fig. 7. Sorption curves for the copolymer (1 mm thick) exposed to $313 \mathrm{~K}$ and ( $\diamond) 10.0 \mathrm{MPa}$; (ם) $15.0 \mathrm{MPa}$ and (+) $18.0 \mathrm{MPa}$.

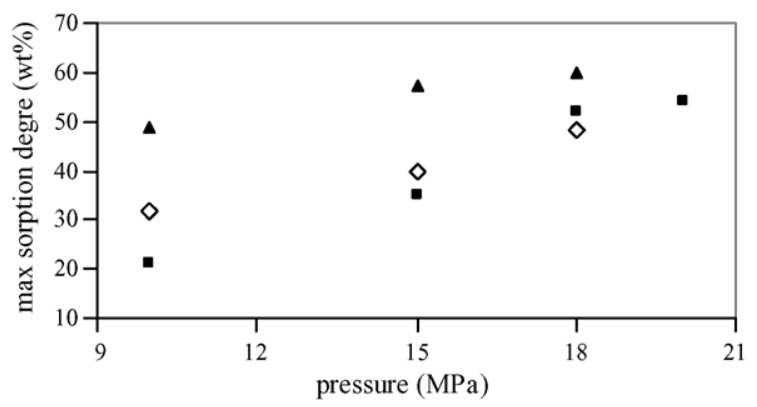

Fig. 8. Equilibrium sorption isotherms as a function of pressure at different temperatures: $(\boldsymbol{\Delta}) 308 \mathrm{~K} ;(\diamond) 313 \mathrm{~K}$; and $(\boldsymbol{\square}) 323 \mathrm{~K}$ for the copolymer with $1 \mathrm{~mm}$ thickness.

$[14,21,22]$ with distinct polymers. Kazarian and co-workers $[14,23]$ have demonstrated spectroscopically the existence of specific interactions between carbon dioxide and various polymers, most probably of Lewis acid-base nature. This author has also pointed out the exothermic nature of this interaction.

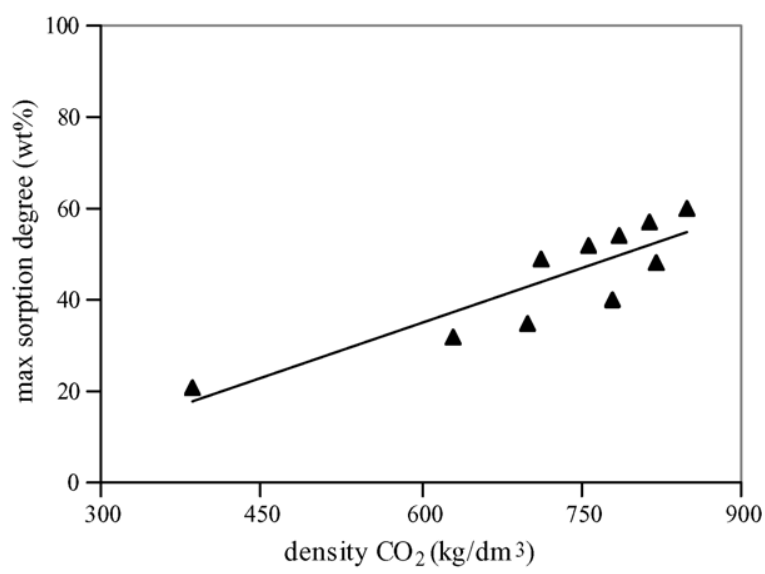

Fig. 9. Maximum sorption degree as a function of carbon dioxide density.
Fig. 8 evidences that a crossover region is being reached at pressures above 18.0 MPa.

\subsection{Sorption kinetics and sorption diffusion coefficient}

The value of the sorption diffusion coefficient is obtained from the slope of $\ln \left(1-\left(M(t) / M_{0}\right)\right)$ as a function of $\left(t / l^{2}\right)$, as it has been previously described. The linearity of Fick's equation is only verified for sorption degree values up to $60 \%$ of the $M_{0}$. Therefore, experiments with a very short period of exposure to carbon dioxide were performed.

The results obtained are presented in Table 1, that summarizes the maximum sorption degree, desorption and sorption coefficients for the different experiments performed.

It was observed that the sorption diffusion coefficients are relatively insensitive to pressure and temperature apart from the value obtained for the experiment at $18.0 \mathrm{MPa}$ and $313 \mathrm{~K}$.

The sorption diffusion coefficients determined have an associated error of $\pm 10 \%$, that was calculated based on the error of the mass of carbon dioxide sorbed in the copolymer. Measurements were performed only for the $1 \mathrm{~mm}$ thick samples.

\subsection{Desorption kinetics and desorption diffusion coefficient}

The desorption diffusion coefficients were calculated from the modeling of the desorption experimental data using Eq. (3).

The maximum value for the desorption diffusion coefficient is $2.30 \times 10^{-9} \mathrm{~m}^{2} / \mathrm{s}$ obtained at $20.0 \mathrm{MPa}$ and $323 \mathrm{~K}$.

In Table 1, the results of the experiments performed are summarized and the variables evidenced. The experiments lead to higher values for the desorption diffusion coefficient than for the sorption diffusion coefficient. Tang et al. [21,22] described a similar behavior in their experiments with polycarbonate and polysulfone. It was suggested that the plasticizing effect of the $\mathrm{CO}_{2}$ is responsible for this tendency. Even though sorption takes place under supercritical conditions and desorption proceeds at 
Table 1

Comparison of maximum sorption degree, desorption and sorption coefficients for the different experiments performed

\begin{tabular}{|c|c|c|c|c|c|c|c|}
\hline$T(\mathrm{~K})$ & $P(\mathrm{MPa})$ & $\begin{array}{l}\rho_{\mathrm{CO} 2} \\
\left(\mathrm{~g} \mathrm{~L}^{-1}\right)^{\mathrm{a}}\end{array}$ & $\begin{array}{l}\text { Thickness } \\
(\mathrm{mm})\end{array}$ & $\%$ iniciator & $\begin{array}{l}\text { Max. sorption } \\
\text { degree }(\%)\end{array}$ & $\begin{array}{l}\text { Desorption diffusion } \\
\text { coeff. } \times 10^{-10}\left(\mathrm{~m}^{2} / \mathrm{s}\right)\end{array}$ & $\begin{array}{l}\text { Sorption diffusion } \\
\text { coeff. } \times 10^{-10}\left(\mathrm{~m}^{2} / \mathrm{s}\right)\end{array}$ \\
\hline \multirow[b]{2}{*}{308} & 10.0 & 713.49 & 1 & 1 & 49 & 7.5 & 1.6 \\
\hline & 15.0 & 815.73 & 1 & 1 & 57 & 6.5 & 0.9 \\
\hline \multirow{4}{*}{313} & 10.0 & 629.94 & 0.5 & 1 & 34 & 0.6 & n.d. \\
\hline & 10.0 & 629.94 & 1 & 1 & 34 & 7.5 & 1.1 \\
\hline & 15.0 & 780.85 & 1 & 1 & 40 & 9.4 & 1.4 \\
\hline & 18.0 & 820.26 & 1 & 1 & 48 & 5.3 & 4.1 \\
\hline \multirow{4}{*}{323} & 10.0 & 384.81 & 1 & 1 & 21 & 7.5 & 1.9 \\
\hline & 15.0 & 700.24 & 1 & 1 & 35 & 7.8 & 0.9 \\
\hline & 18.0 & 757.68 & 1 & 1 & 52 & 22.0 & 1.0 \\
\hline & 20.0 & 784.95 & 1 & 1 & 54 & 23.0 & n.d. \\
\hline
\end{tabular}

a Allprops-Thermodynamic Properties of Fluids, Program from the Center of Applied Thermodynamic Studies College of Engineering, University of Idaho, Moscow, Idaho, 1991.

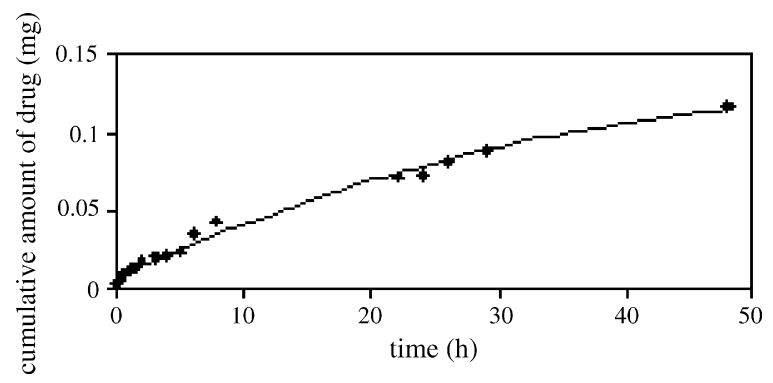

Fig. 10. In vitro release profiles of drug from the film ( $0.5 \mathrm{~mm}$ thickness) impregnated at $18.0 \mathrm{MPa}, 313 \mathrm{~K}$ for $2 \mathrm{~h}$.

ambient temperature and pressure, the release of carbon dioxide from the polymeric matrix during desorption is faster, due to the higher chain mobility of the polymer substrate that has been exposed to high pressure and temperature.

To investigate the possibility of impregnating this acrylate copolymer with an anti-inflammatory drug (flurbiprofen), a preliminary experiment was performed. Briefly, a saturated stream of a pharmaceutical compound in carbon dioxide passed through the polymeric matrix and the $\mathrm{CO}_{2}$ flow was maintained at a very low rate so that the impregnation could take place. The impregnation process of the copolymer $(0.5 \mathrm{~mm}$ thick) at $313 \mathrm{~K}$ and 18.0 MPa last for $2 \mathrm{~h}$. The release studies were performed in physiological salt solution at $37.0 \pm 0.5^{\circ} \mathrm{C}$ and samples were withdrawn at predetermined time intervals. The amount of drug in the samples was measured by a Genesys 10 UVscanning (Thermospectronic) spectrophotometer and the cumulative amount of drug release from the films was calculated based on all collected samples (Fig. 10).

\section{Conclusions}

This study reports the sorption degree and diffusion coefficients for the cross-linked copolymer P(MMA-EHA-EGDMA). The copolymer presented Fickian behavior and Fick's diffusion model was applied to determine the amount of carbon dioxide present and the diffusion coefficients. The sorption degree was found to be higher for lower temperatures and increased with increasing pressure. Sorption diffusion coefficients were calculated for the samples $1 \mathrm{~mm}$ thick and showed to be relatively insensitive to pressure or temperature. The desorption diffusion coefficients were determined for ambient conditions and the values obtained were higher than the ones obtained for the sorption that took place under supercritical conditions. Samples of P(MMA-EHA-EGDMA) with different thickness were used for comparison of the maximum sorption degree and the solubility of carbon dioxide in the copolymer was not affected by its thickness. Polymerization conditions were also varied in order to evaluate the influence of the molecular weight of the copolymer in the $\mathrm{CO}_{2}$ sorption process. It was observed that the amount of carbon dioxide sorbed in the copolymer is higher when the copolymer has a lower molecular weight. Preliminary impregnation studies were performed to evaluate the possibility of using this copolymer for improved delivery systems with ophthalmic applications.

\section{Acknowledgements}

Ana Rita C. Duarte is grateful for financial support from SFRH/BD/10780/2002 grant. This work was financially supported by FCT-MCES and FEDER, Portugal, under contract POCTI/FCB/38213/2001.

\section{References}

[1] S.G. Kazarian, Polymer processing with supercritical fluids, Polym. Sci., Ser. C 42 (2000) 78-101.

[2] A.I. Cooper, Polymer synthesis and processing using supercritical carbon dioxide, J. Mater. Chem. 10 (2000) 207-234.

[3] M. Mariz, Preparação de uma lente intra-ocular dotada de um sistema de libertação controlada de fármaco, Master thesis, Universidade de Coimbra, 1999. 
[4] H.T. Jespersen, Studies of sorption and modification of polymer films in supercritical carbon dioxide, Master thesis, University of Copenhagen, 2002.

[5] I. Kikic, P. Sist, Applications of supercritical fluids to pharmaceuticals: controlled drug delivery systems, in: E. Kiran, P.G. Debenedetti, C.J. Peters (Eds.), Supercritical I. Fluids: Fundamentals and Applications, Proceedings of the 2nd NATO ASI on Supercritical Fluids, NATO, Science Series, Kluwer Academic Publishers, Dordrecht, Netherlands, 2000, pp. 291-306.

[6] S. Angus, B. Amstrong, K.M. Reuck (Eds.), International Thermodynamic Tables of the Fluid State Carbon Dioxide, IUPAC, vol. 3, Pergamon Press, 1976.

[7] L.N. Nikitin, M.O. Gallyamov, R.A. Vinokur, A.Y. Nikolaec, E.E. SaidGaliyev, A.R. Khokhlov, H.T. Jespersen, K. Shaumburg, Swelling and Impregnation of polysterene using supercritical carbon dioxide, J. Supercrit. Fluids 26 (2003) 263-273.

[8] A.R. Berens, G.S. Huvard, R.W. Korsmeyer, F.W. Kunig, Application of compressed carbon dioxide in the incorporation of additives into polymers, J. Appl. Polym. Sci. 46 (1992) 231-242.

[9] J.J. Watkins, T.J. McCarthy, Polymerization of styrene in supercritical CO-swollen poly(chlorotrifluoroethylene), Macromolecules 28 (1995) 4067-4074.

[10] Y. Zhang, K.K. Gangwani, R.M. Lemert, Sorption and swelling of block copolymers in the presence of supercritical fluid carbon dioxide, J. Supercrit. Fluids 11 (1997) 115-134.

[11] J.H. Aubert, Solubility of carbon dioxide in polymers by the quartz crystal microbalance technique, J. Supercrit. Fluids 11 (1998) 163-172.

[12] R.G. Wissinger, M.E. Paulaties, Swelling and sorption in polymer- $\mathrm{CO}_{2}$ mixtures at elevated pressures, J. Polym. Sci. Polym. Phys. 25 (1987) $2497-2510$.
[13] J.R. Fried, W. Li, High-pressure FTIR studies of gas-polymer interactions, J. Appl. Polym. Sci. 41 (1990) 1123-1131.

[14] N.H. Brantley, S.G. Kazarian, C.A. Eckert, In situ FTIR measurement of carbon dioxide sorption into poly(ethylene terephthalate) at elevated pressures, J. Appl. Polym. Sci. 77 (2000) 764-775.

[15] J. Crank, Diffusion in Polymers, Academic Press, London, 1968.

[16] J. Crank, The Mathematics of Diffusion, Oxford Science Publications, Oxford, 1975.

[17] L.N. Nikitin, E.E. Said-Galiyev, R.A. Vinokur, A.R. Khokhlov, Poly(methylmethacrylate and poly(buthylmethacrylate) swelling in supercritical carbon dioxide, Macromolecules 35 (2002) 934-940.

[18] K.F. Webb, A.S. Teja, Solubility and diffusion of carbon dioxide in polymers, Fluid Phase Equilib. 158-160 (1999) 1029-1034.

[19] N.M.B. Flichy, Effects of high-Pressure CO2 on polymeric materials: spectroscopy and rheology, Ph.D. Thesis, Imperial College, London, 2002.

[20] P.G. Shewmon, Diffusion in Solids, McGraw Hill, New York, 1963.

[21] M. Tang, T.-Z. Du, Y.-P. Chen, Sorption and diffusion of supercritical carbon dioxide in polycarbonate, J. Supercrit. Fluids 28 (2004) 207218.

[22] M. Tang, T.-Z. Du, Y.-P. Chen, Sorption and diffusion of supercritical carbon dioxide in polysulfone, J. Appl. Polym. Sci. 94 (2004) 474 482

[23] S.G. Kazarian, M.F. Vincent, F.V. Bright, C.L. Liotta, C.A. Eckert, Specific molecular interaction of carbon dioxide with polymers, J. Am. Chem. Soc. 118 (1996) 1729-1736.

[24] A.R.C. Duarte, L.E. Anderson, C.M.M. Duarte, S.G. Kazarian, A comparison between gravimetric and in situ spectroscopic methods to measure the sorption of $\mathrm{CO}_{2}$ in a biocompatible polymer, J. Sup. Fluids 36 (2005) $160-165$. 